Supporting information for

\title{
Study on the effect of stretching on the strength of natural silk based on different feeding methods
}

Jianwei Qu a, Piao Feng a, Qingyu Zhu a, Yuying Ren a , Bing Li a, b, *

${ }^{a}$ School of Basic Medicine and Biological Sciences, Soochow University, Suzhou, Jiangsu 215123, P.R. China

b Sericulture Institute of Soochow University, Suzhou, Jiangsu 215123, P.R. China

* Corresponding author: Bing Li

Institute: School of Basic Medic and Biological Sciences, Soochow University

Postal address: Suzhou 215123, Jiangsu, China

E-mail: lib@suda.edu.cn

Fax: $+86-512-65880262$ 
a

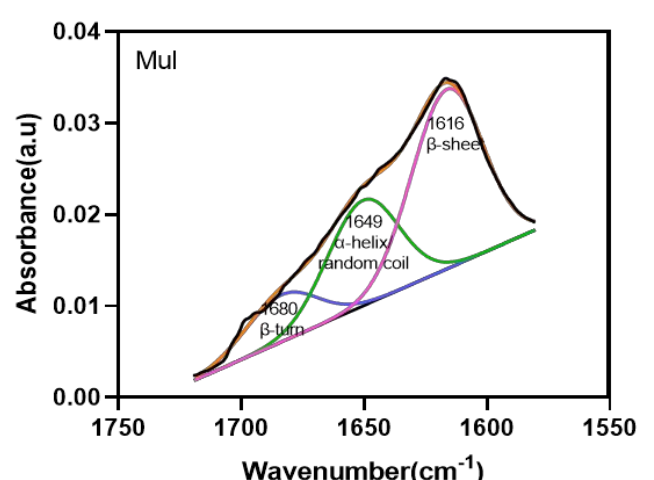

b

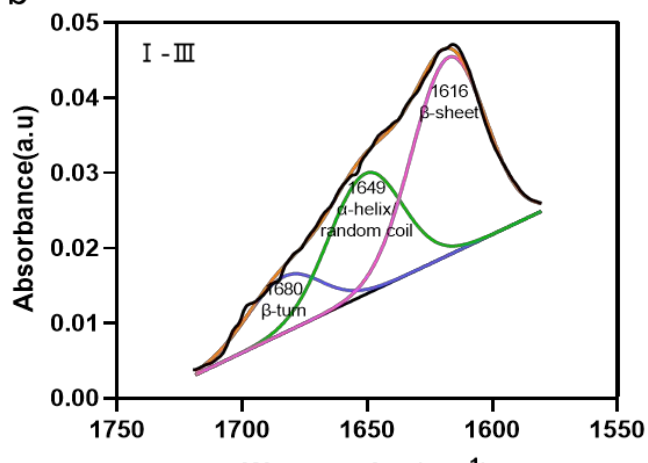

C

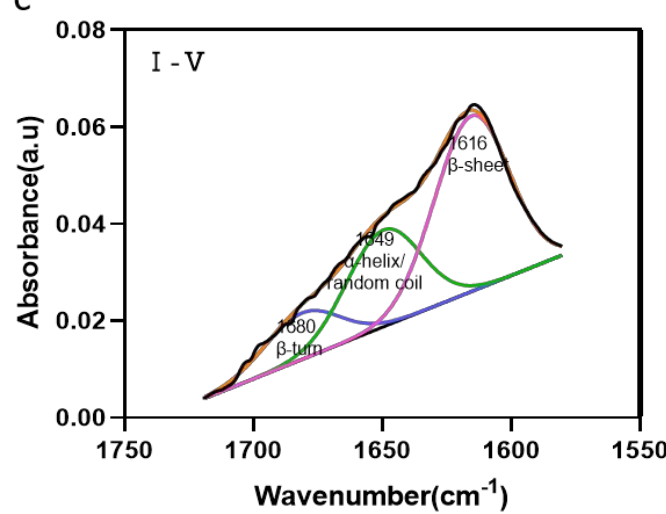

d

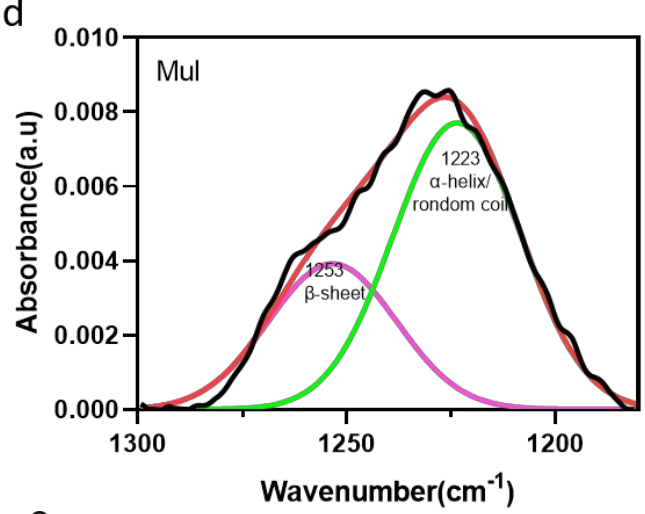

e

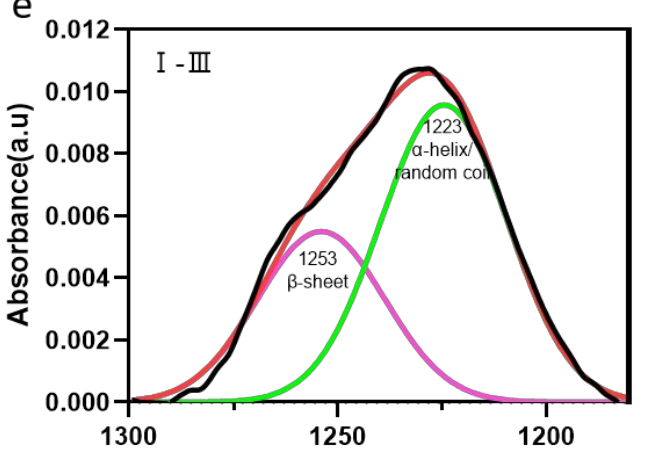

Wavenumber $\left(\mathrm{cm}^{-1}\right)$

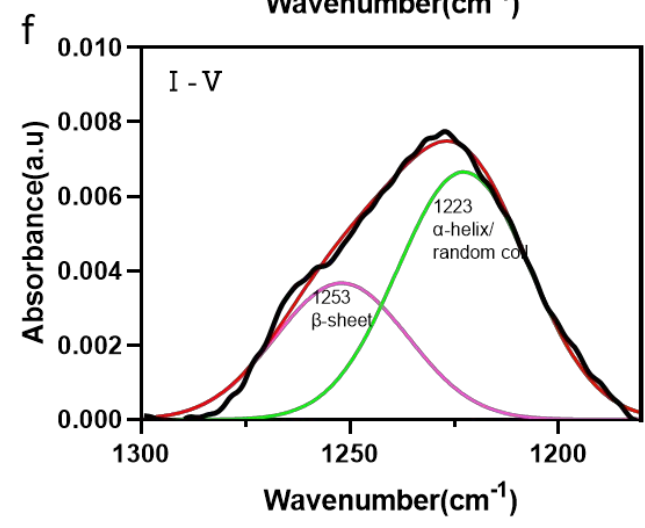

Fig. S1. The deconvolution process of silk infrared spectrogram. 

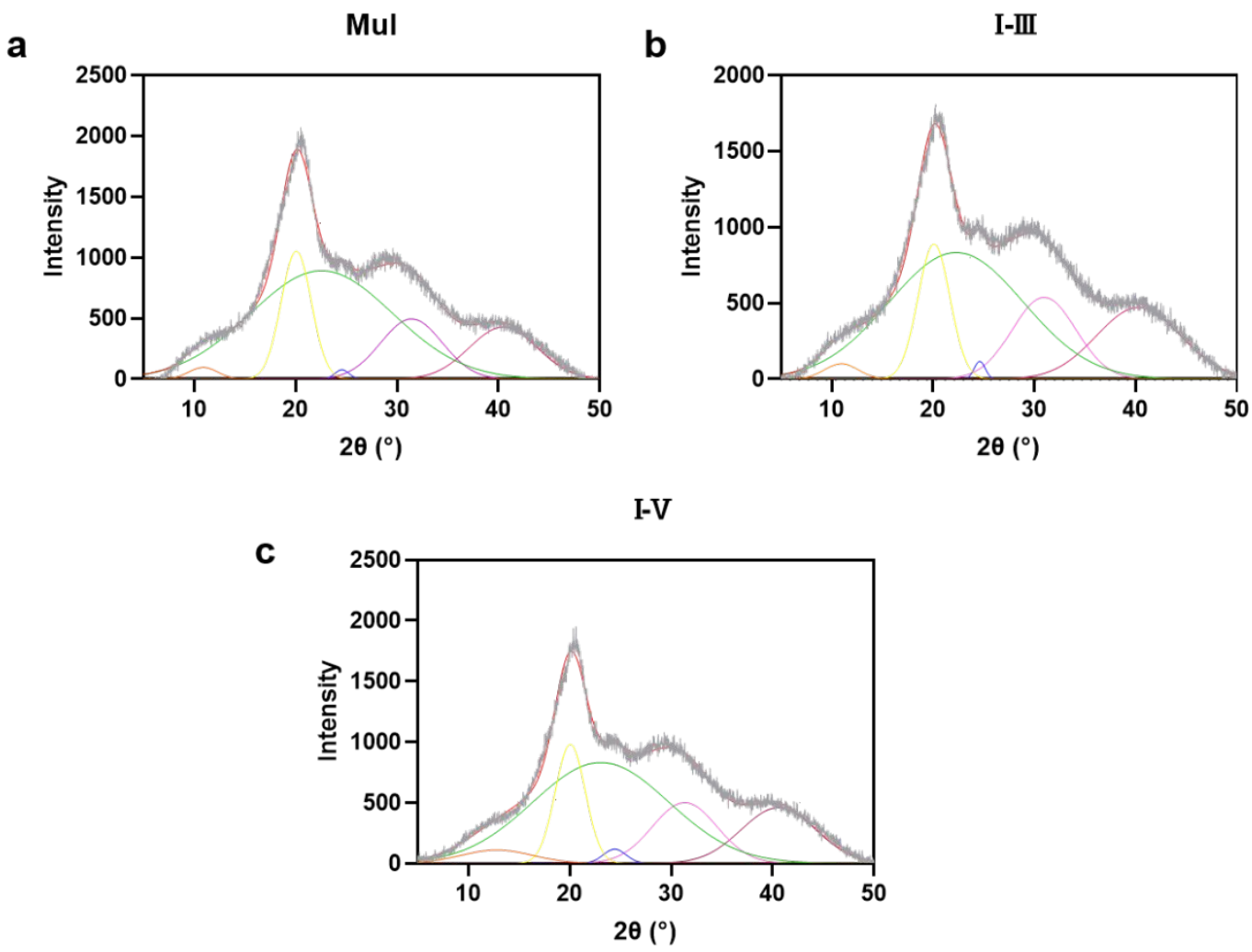

Fig. S2. The deconvolution process of silk X-ray diffraction pattern.

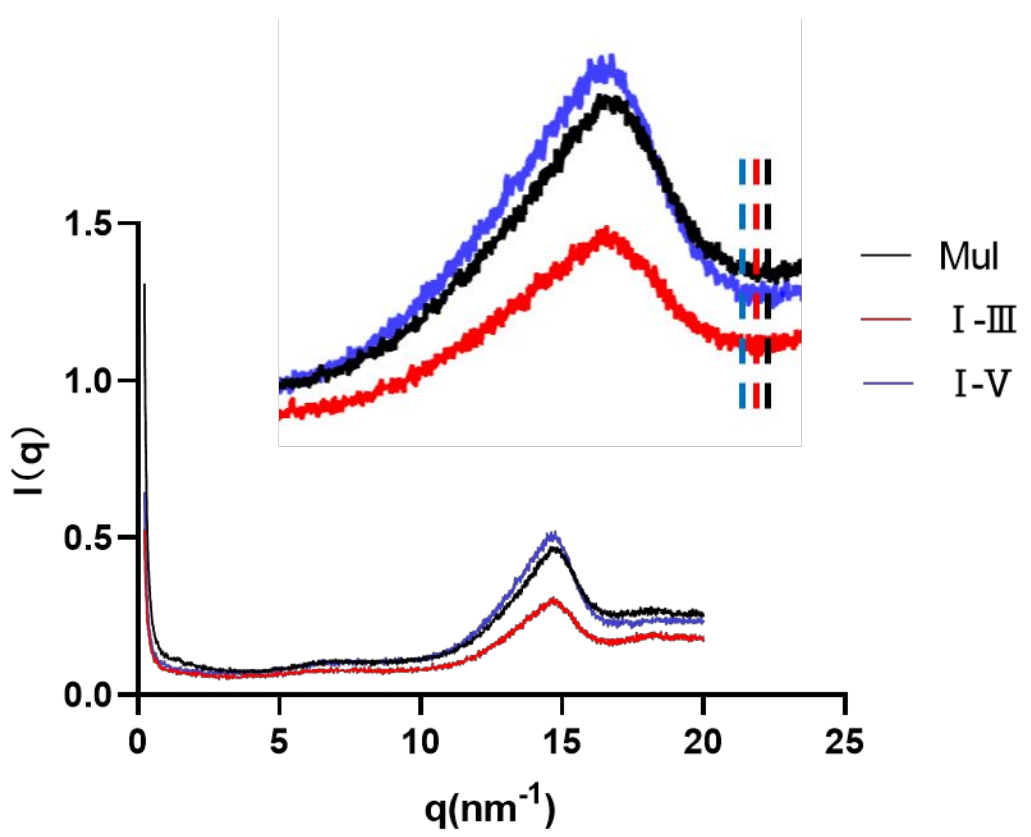

Fig. S3. The SAXS data image. 